CLINICAL STUDY

\title{
Serum IGF 1 and insulin levels in girls with normal and precocious puberty
}

\author{
Kaspar Sørensen, Lise Aksglaede, Jørgen Holm Petersen ${ }^{1}$, Anna-Maria Andersson and Anders Juul \\ Department of Growth and Reproduction, GR-5064, Copenhagen University Hospital, Blegdamsvej 9, DK-2100 Copenhagen, Denmark and \\ ${ }^{1}$ Department of Biostatistics, University of Copenhagen, Copenhagen, Denmark
}

(Correspondence should be addressed to K Sorensen; Email: kaspar.soerensen@rh.regionh.dk)

\begin{abstract}
Objective: IGF1 plays an important role in growth and metabolism during puberty. IGF1 levels are increased in girls with central precocious puberty (CPP). However, the relationship with insulin before and during gonadal suppression is unknown. In addition, the influence of the exon 3-deleted GH receptor gene (GHRd3) on IGF1 levels was evaluated.

Design: Nine hundred and eleven healthy and 23 early pubertal girls (15 with CPP) participated and were evaluated by dual-energy X-ray absorptiometry (DXA) scans, fasting and oral glucose-stimulated insulin levels, IGF1 levels, and GHR genotyping. Fifteen girls with early puberty (13 with CPP) were treated with GNRH agonists and reevaluated after 3 and 12 months.

Results: IGF1 and insulin levels were higher in girls with CPP compared with healthy controls after adjustment for age, bone age, and breast development (all $P \leq 0.02$ ). IGF1 levels were only significantly positively correlated with insulin levels in girls with $\mathrm{CPP}$ at baseline $(P \leq 0.03)$. During gonadal suppression, changes in IGF1 levels were inversely associated with changes in insulin levels $(P=0.04)$. The GHRd3/d3 genotype was associated with significantly higher IGF1 levels $(P=0.01)$ but not with earlier pubertal timing in healthy girls. The distribution of the GHRd3 genotypes among girls with CPP did not differ significantly from healthy girls $(P=0.2)$.

Conclusion: The increased IGF1 and insulin levels in girls with CPP may be causally interrelated. In addition, the GHRd3 allele positively influences IGF1 levels in a copy number-response relationship but not pubertal timing in healthy girls.
\end{abstract}

European Journal of Endocrinology 166 903-910

\section{Introduction}

The role of the GH/insulin-like growth factor 1 (IGF1) axis as a modulator of maturational timing is increasingly recognized $(1,2,3)$. In healthy girls, higher childhood IGF1 levels predict earlier age at menarche (4), and girls with central precocious puberty (CPP) have higher IGF1 levels than accounted for by the advancement in bone age (BA) at time of diagnosis (5). In female rodents, central and peripheral IGF1 treatment advances age at vaginal opening $(6,7,8)$, possibly through direct stimulatory effects on hypothalamic GNRH $(7,9)$ and kisspeptin neurons (10). Accordingly, GNRH neuron-specific IGF1 receptor knockout mice have delayed vaginal opening (7). Thus, IGF1 seems permissive for normal female pubertal timing and may even be able to advance time of puberty if prepubertal levels are elevated. Similar to IGF1, higher prepubertal insulin levels predict earlier age at menarche (11). Accordingly, we have recently shown that insulin sensitivity is decreased in girls with CPP at diagnosis and is aggravated further during gonadal suppression (12). However, to what extent this may be due to changes in IGF1 levels during gonadal suppression is unresolved.

The GH/IGF1 axis has a major influence on glucose homeostasis (13). In healthy girls, insulin sensitivity decreases approaching mid-puberty after which a partial recovery is generally seen $(14,15)$. This curvilinear pattern is associated with the increased activity of the GH/IGF1 axis (14). However, GH and IGF1 have opposing influences on insulin sensitivity (16). While $\mathrm{GH}$ antagonizes the hepatic and peripheral effects of insulin, IGF1 may partly counteract these effects through downregulation of $\mathrm{GH}$ secretion as well as through direct insulin-like effects (17). In accordance with the latter, IGF1 treatment decreases insulin levels in patients with GH deficiency (16) and insensitivity (18).

Another vital component of the GH/IGF1 axis is the GH receptor (GHR). In rodents as well as in humans, defective GH signaling due to loss-of-function mutations in the GHR gene is associated with GH resistance and IGF1 deficiency leading to enhanced insulin sensitivity as well as delayed onset and slower progression of puberty (19, 20). In contrast, a common gain-of-function GHR variant (21) differing from the wild-type gene (full length, GHRfl) 
by exclusion (deleted, GHRd3) of exon 3 has recently been associated with increased IGF1 levels in childhood and with early onset of clinical and biochemical signs of puberty in boys (22). In addition, the presence of the GHRd3 allele has been associated with increased insulin secretion in a mixed cohort of healthy pubertal children (15). To our knowledge, no previous studies have evaluated the potential role of this genetic polymorphism for timing of puberty in girls. In addition, the influence of the GHRd3 allele on IGF1 levels in healthy girls has been discordant $(15,22,23)$ despite the fact that shortterm GH stimulation seems to enhance IGF1 levels more in the presence of the GHRd3 allele compared with GHRfI homozygotes (24). Thus, the higher IGF1 levels observed in girls with CPP may be related to a higher prevalence of this genetic polymorphism.

Thus, we hypothesize that girls with early puberty have higher IGF1 levels compared with normally timed pubertal girls and that these differences may be associated with differences in glucose homeostasis and/or with the presence of the GHRd3 allele.

Our aim was to evaluate i) serum IGF1 and insulin levels in normal-timed pubertal girls and in girls with CPP before and during gonadal suppression and ii) the influence of the GHRd3 allele on serum IGF1 and pubertal timing.

\section{Materials and methods}

\section{Participants}

The study population consisted of two cohorts. All healthy subjects were recruited as a part of The Copenhagen Puberty Study from primary schools in the Copenhagen Community. Nine hundred and eleven girls aged 5.6-20.2 years volunteered. The influence of the GHRd3 allele on IGF1 levels and pubertal timing as well as differences in IGF1 levels between healthy girls and girls with early puberty were evaluated in this cohort. Other aspects of this study have previously been published (25). In brief, clinical evaluations included auxology (height and weight), and pubertal staging according to Tanners classification was performed (26). In 115 of the 911 healthy girls, body composition was additionally evaluated by dual-energy X-ray absorptiometry (DXA) scans (Hologic CDR 1000/W densitometer; Hologic, Inc., Bedford, MA, USA) and body fat percentage $(\mathrm{BF} \%)$ was calculated. In addition, glucose metabolism was evaluated by oral glucose tolerance tests (OGTTs) in these girls. This sub-cohort was used for the evaluation of the relationship between IGF1 and insulin parameters as well as the evaluation of differences in insulin levels between healthy girls and girls with early puberty.

Twenty-three girls were included with either early normal puberty (EP, $n=8$ ) or with idiopathic CPP $(n=15)$. All these girls were recruited from our outpatient clinic at the Department of Growth and Reproduction, Copenhagen University Hospital, from May 2008 to September 2009. The diagnosis of CPP was made if the following criteria were met: onset of breast development before the age of 8 years, a $30 \mathrm{~min}$ peak LH level above $5 \mathrm{IU} / \mathrm{l}$, or a peak LH/FSH ratio of 0.66 in response to rapid-acting GNRH agonist (GNRHa). The same criteria were applied to girls with EP, except for age at onset of puberty between 8 and 9 years. All girls with CPP had a nonpathological brain magnetic resonance imaging (MRI scan). BA was advanced in girls with EP (0.87 (0.49-1.26) years) and CPP (1.25 (0.81-1.69) years) at baseline. Fifteen girls with early puberty (CPP, $n=13)$ were initiated on depot GNRHa treatment (3.75 mg Procren) with injections every 28th day and followed with reevaluations after 3 and 12 months of treatment. All reevaluations during treatment were done on days of injections. Other aspects of this study have previously been published (12).

\section{Analyses}

Blood samples were drawn from the antecubital vein into standard vacuum tubes. From the majority of controls $(n=796)$, nonfasting blood samples were available, whereas fasting blood samples were obtained from the 115 girls with supplementary DEXA scans. In addition, standard $120 \mathrm{~min}$ OGTT (1.75 g of glucose/kg bodyweight, max. $75 \mathrm{~g}$ ) with $30 \mathrm{~min}$ sampling intervals for determination of blood glucose and insulin was performed in these 115 girls. Fasting blood samples were available from all girls with $\mathrm{EP}$ and $\mathrm{CPP}$ at all visits. In addition, OGTTs were performed in 18 patients $(n=12$ with (PP) at baseline. Of the 15 patients initiated on GNRHa, OGTTs were performed in 11 at the 3-month follow-up and 9 at the 1-year follow-up visit.

IGF1 and IGFBP 3 levels were determined by Immulite 2000 IGF1/IGFBP3 (Siemens Healthcare Diagnostics, Tarrytown, NY, USA) on automated Immulite 2000 (Siemens Healthcare Diagnostics). For IGF1 and IGFBP3, the intra- and interassay coefficients of variation (CV) were below 4 and 9\% respectively. Estradiol $\left(\mathrm{E}_{2}\right)$ was measured using Pantex $E_{2}$ (Pantex, Santa Monica, CA, USA). The detection limit was $18 \mathrm{pmol} / \mathrm{l}$; the intra- and interassay CV were $<8$ and $13 \%$ respectively. Insulin and glucose were determined on automated Roche Modular Analytics (SWA) Modules with Elecsys insulin and GLU assays (Roche Diagnostics). Insulin and glucose are expressed as fasting plasma insulin (FPI) and fasting plasma glucose (FPG) levels as well as mean plasma insulin (MPI) and mean plasma glucose (MPG) levels during the OGTT calculated from the area under the curve. HbAlc was evaluated using Tosoh G7 (Tosoh bioscience, Tokyo, Japan).

Genomic DNA was extracted from blood lymphocytes. The frequency of GHR transcript variants with retention (GHRfl) or exclusion (GHRd3) of exon 3 was tested by 


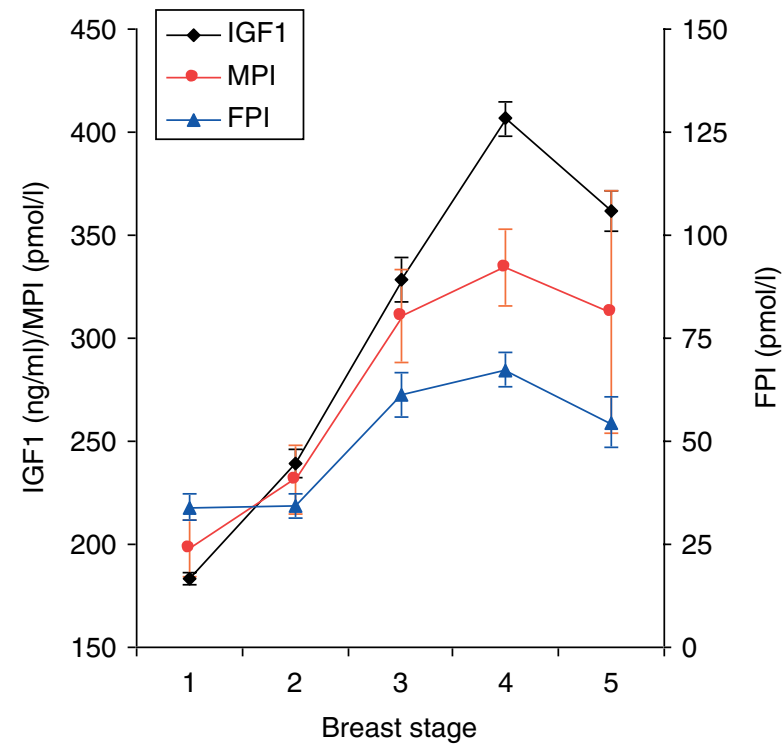

Figure 1 Levels of IGF1, FPI, and oral glucose-stimulated insulin (MPI during oral glucose tolerance test) in relation to pubertal development (breast stage I-V) in 911 (IGF1) and 115 (FPI and MPI) healthy girls. Data are shown as mean \pm S.E.M.

the multiplex PCR assay as described by Pantel et al. (27). Further details have previously been published $(15,22)$. Genotyping for the GHRd3 allele was obtained in 906 of the healthy girls and all the EP and CCP patients. Genotyping could not be obtained in five of the healthy girls due to missing or degraded DNA. The distribution of the GHR genotypes did not deviate significantly from the Hardy-Weinberg equilibrium $(P>0.25)$.

\section{Statistical analysis}

Results are presented as mean and 95\% confidence intervals unless otherwise stated. Group comparisons were made with Students $t$-tests. Univariate analysis of variance (ANOVAs) were used to analyze IGF1 and insulin levels between groups adjusted for age, bone age pubertal stage respectively. IGF1 and insulin levels were log-transformed before analyses in order to obtain approximate normal distribution of the residuals as well as a residual variation that did not depend on the level. Owing to the complex biphasic relationship between IGF1 and age, the statistical model included age as both continuous and group variable (below 10.0, 10.0-13.9 and above 14.0 years) as well as the interaction between the two (age*age group). Similar for the relationship between IGF1 and pubertal stage, both age, pubertal stage, and the interaction between the two was included in models when adjusting for both age and pubertal stage (age*pubertal stage). Longitudinal changes during GNRHa treatment were evaluated by paired Student's t-tests. Interrelated changes in main outcome variables during gonadal suppression were evaluated by Pearson's correlation. Mean ages at entry into $\mathrm{B} 2$ and $\mathrm{PH} 2$ and age at menarche were estimated by Probit analysis. The Hardy-Weinberg equilibrium and prevalence of GHR genotypes were assessed with $\chi^{2}$ tests.

\section{Ethics}

The study (clinicaltrials.gov \#NCT01411527) was conducted in accordance with the ethnical principles of the Helsinki II declaration. The study protocol was approved by the Local Ethics Committee (ref no. KF 01 282214 and KF 11 2006-2033). All children and parents gave their written informed consent.

\section{Results}

\section{IGF1 levels in girls with normal and precocious puberty}

In healthy girls, IGF1 levels increased significantly between each breast and pubic hair stage from stage I (prepuberty) to stage IV after which levels decreased between stages IV and V (all $P<0.004$; Fig. 1). A similar curvilinear pattern was seen with age $(P<0.001$; Fig. 2). Age was positively associated with IGF1 levels in breast stages I and III and negatively associated with age in breast stages IV and $V$ (all $P<0.03$ ) respectively. No association was found between age and IGF1 levels in breast stage II. IGFBP3 levels were significantly associated with age and pubertal stage in healthy controls in a similar pattern to IGF1 (both $P<0.001$ ).

At the time of diagnosis, girls with EP and CPP had significantly higher IGF1 levels compared with agematched healthy girls $(P=0.002$ and $<0.001$ respectively; Fig. 2). BA and stage of breast development, but not chronological age (CA), were positively associated with IGF1 levels in girls with EP and CPP (both $P \leq 0.001$ ).

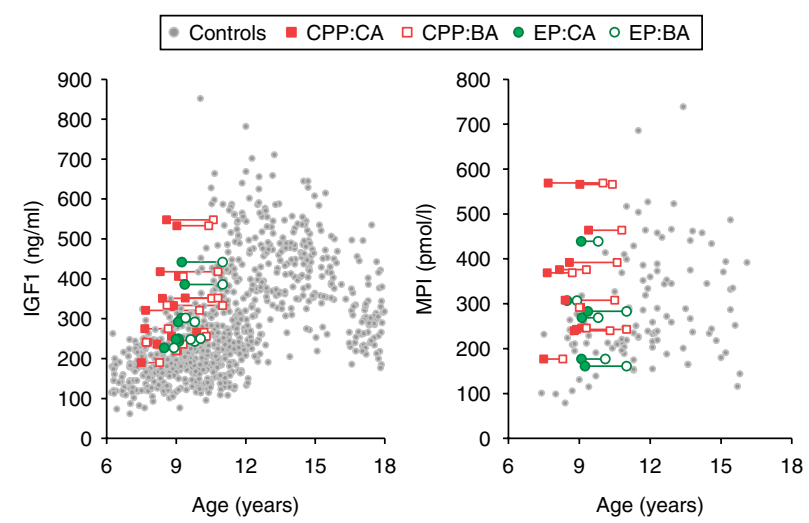

Figure 2 IGF1 and MPI in relation to CA and BA in 23 girls with EP or CPP compared with healthy girls. Data are presented in green circles for girls with EP and in red squares for girls with CPP. Solid circles/squares represent the level according to CA and open circles/squares represent the level according to BA. Lines between circles/squares connect $\mathrm{CA}$ with $\mathrm{BA}$ in the individual patients and represent the $\mathrm{BA}$ advancement. 
After adjustment for BA, girls with EP and CPP still had higher IGF1 levels at baseline than the healthy girls $(P=0.029$ and $<0.001$ respectively; Fig. 2$)$. In addition, girls with CPP had higher IGF1 levels than breast stagematched healthy girls $(P=0.027)$. IGF 1 levels were not associated with $\mathrm{BF} \%$ in neither healthy girls nor girls with CPP. Accordingly, the abovementioned differences in IGF1 levels between groups remained significant after adjustment for $\mathrm{BF} \%$. Girls with $\mathrm{CPP}$ had significantly higher IGFBP3 levels adjusted for age (10.5 (0.6-21.4) $\%, P=0.04)$, but not adjusted for BA or breast development, compared with the healthy girls. No differences in IGFBP3 levels were found between girls with EP and controls.

\section{Insulin levels and relation to IGF1 in girls with normal and precocious puberty}

In healthy girls, FPI and MPI levels paralleled the pattern of IGF1 levels during puberty (Fig. 1). Accordingly, IGF1 levels were positively associated with FPI $(P=0.001)$ and MPI $(P=0.003)$ after adjustment for age and pubertal stage. Within each breast stage, IGF1 levels were strongly correlated with FPI and MPI in breast stages III and IV respectively $(r=0.32, P=0.048$, and $r=0.43, P=0.036$ respectively). FPI and MPI levels (Fig. 2) were significantly higher in girls with $\mathrm{EP}$ and CPP compared with healthy girls matched for $\mathrm{CA}$ and $\mathrm{BA}$ (all $\mathrm{P} \leq 0.004)$. The girls with $\mathrm{CPP}$ showed significantly higher MPI levels than pubertal stagematched healthy controls $(P=0.04)$. All the abovementioned differences in insulin levels between girls with CPP and healthy controls remained significant after additional adjustment for $\mathrm{BF} \%(P \leq 0.05)$. Similar to the finding in healthy girls, IGF1 was positively associated with FPI $(P=0.03)$ and MPI $(P=0.02)$ after adjustment for pubertal stage in girls with CPP at baseline. FPG, MPG, or HbAlc levels were not associated with IGF1 in neither healthy girls nor girls with EP and CPP. No differences were found in FPG, MPG, or HbAlc between healthy girls and girls with EP and CPP.

\section{Influence of gonadal suppression on IGF1 and insulin levels}

Longitudinal changes in BF\%, IGF1, IGFBP3, $\mathrm{E}_{2}$, MPI, and $\mathrm{HbA} 1 \mathrm{c}$ levels before and during gonadal suppression are shown in Fig. 3. Higher baseline IGF1 and $\mathrm{E}_{2}$ levels as well as more advanced breast development and BA predicted a greater decline in IGF 1 and a greater increase in MPI levels during the first 3 months of GNRHa treatment (all $P \leq 0.02$ ). Pretreatment levels of IGF1 and MPI positively predicted IGF 1 and insulin levels at 3 and 12 months respectively (all $P \leq 0.05$ ). Interrelated changes in $\mathrm{E}_{2}$, IGF1, and MPI levels during gonadal suppression are shown in Fig. 4. The decline in IGF1 was borderline significantly associated with the increase in $\mathrm{HbA1c}$ levels in the first 3 months of GNRHa treatment
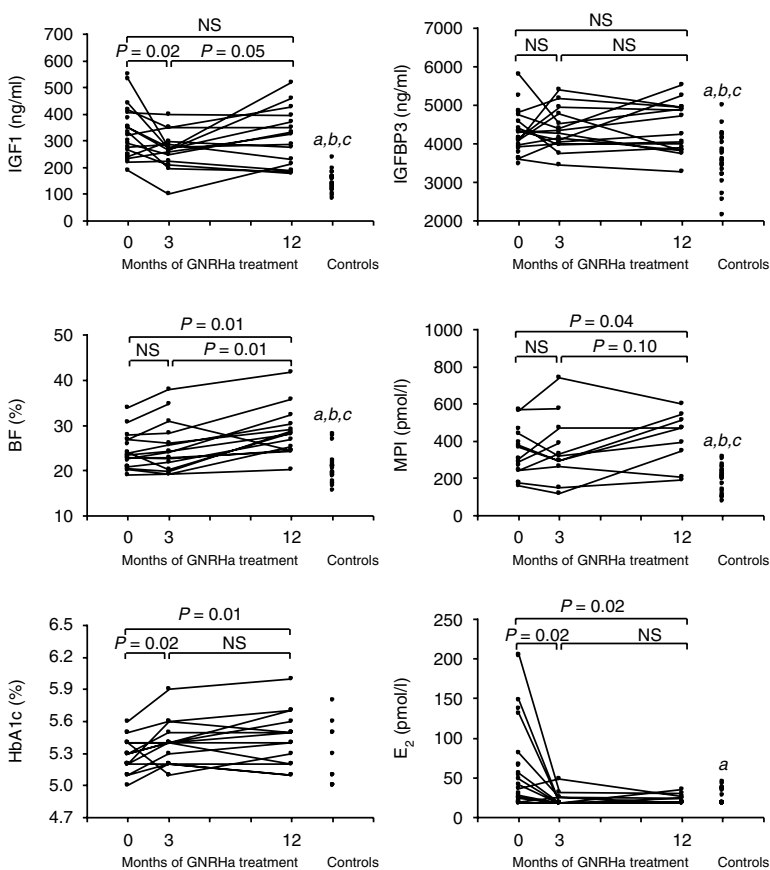

Figure 3 Longitudinal changes in IGF1, IGFBP3, body fat percentage (BF\%), MPI, $\mathrm{HbA} 1 \mathrm{c}$, and $\mathrm{E}_{2}$ levels during gonadal suppression with GNRHa in 15 girls with EP (13 with CPP). Baseline levels of all the above outcomes are shown in all 23 girls (15 girls with (CPP) with EP. Twenty-four prepubertal age-matched controls are shown for reference. Longitudinal changes were evaluated by paired Student's $t$-test. $P>0.10 ; P=N S$ (not significant). Crosssectional comparison with controls was done by Student's $t$-tests. a, $P<0.05$ vs baseline; b, $P<0.05$ vs 3 -month visit; $\mathrm{c}, P<0.05$ vs 12-month visit.

$\left(R^{2}=0.22, P=0.09\right)$. The positive association between IGF1 and MPI and FPI levels at baseline $(P \leq 0.03)$ was no longer present after initiation of GNRHa treatment $(P>0.5)$. Significant positive associations between $\mathrm{BF} \%$ and MPI were present at all time points $(P \leq 0.05)$. No significant changes in FPG or MPG were observed during GNRHa treatment.

\section{Influence of GHRd3 genotype on IGF1 levels and pubertal timing}

The distribution of the three genotypes in the healthy controls was as follows: GHRfl/fl, 488 (53.9\%); GHRfl/d3, 350 (38.6\%); and GHRd3/d3, 68 (7.5\%). The distribution of genotypes in girls with EP was GHRfl/fl: $4(50.0 \%)$ and GHRfl/d3: $4(50.0 \%)$ and in girls with CPP GHRfl/fl: 5 (33.3\%) and GHRfl/d3: 10 (66.6\%). None of the patients had the GHRd3/d3 genotype.

The GHRd 3 allele was significantly positively associated with IGF1 levels in a copy number-response relationship (Fig. 5). After adjustment for pubertal stage and age, the GHRd3/d3 group had significantly higher IGF1 levels compared with the GHRfl/d3 (8.8 (0.6-17.5) \%, $P=0.035)$ and the GHRfl/fl groups (10.8 (2.7-19.6) \%, $P=0.008)$ respectively. IGF1 levels did not differ 

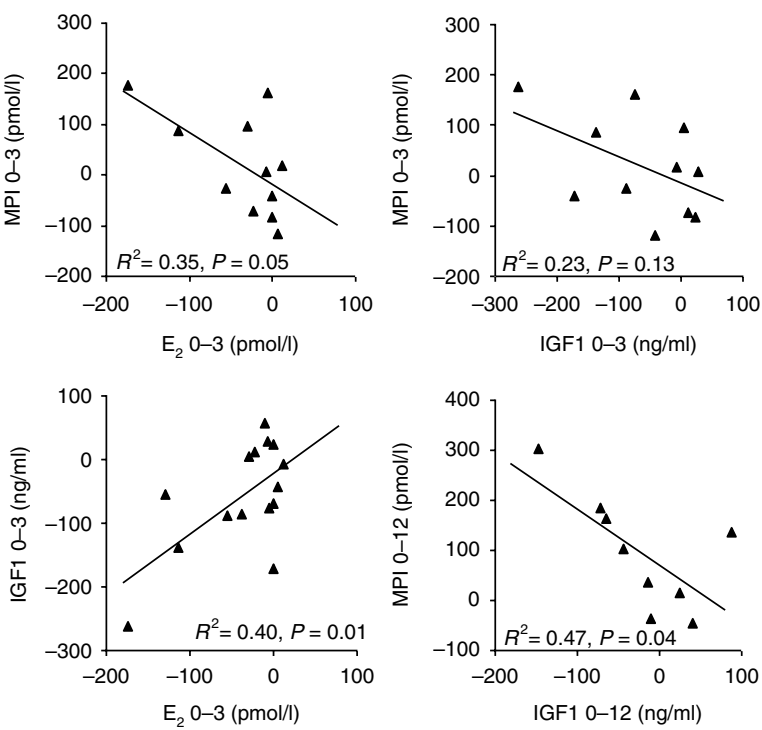

Figure 4 Interrelated changes in $\mathrm{E}_{2}$, IGF1, and MPI levels during the first year of gonadal suppression with GNRHa. Correlations were evaluated by Pearson's correlation coefficients $(r)$ and expressed as $R^{2}$. Changes were evaluated over the two periods: baseline to 3 months $(0-3)$ and baseline to 12 months $(0-12)$. The figures shown represent the statistically strongest correlations between changes in these three hormones over the first year of GNRHa treatment.

statistically between the GHRfl/d3 and the GHRfl/fl groups. No significant differences in IGFBP3 levels were found between any GHR genotypic groups. No significant differences were found in IGF1 or IGFBP 3 levels between the GHR genotypic groups in girls with EP and CPP either at baseline or during gonadal suppression.

In the healthy girls, the mean age at entry into breast stage II, pubic hair stage II, and menarche were 9.9, 11.1, and 13.2 years respectively. No differences were found in age at onset of these pubertal markers between GHRd3 genotypes in healthy girls (all $P>0.2$ ). In girls with EP and CPP, the presence of the GHRd3 allele was not significantly different from that of the healthy girls $(P \geq 0.13)$.

\section{Discussion}

In this study, we found that girls with CPP had increased IGF1 as well as increased fasting and oral glucosestimulated insulin levels compared with healthy girls after adjustment for age, BA, and pubertal stage respectively. IGF1 levels were significantly positively associated with insulin levels in both healthy girls and in girls with CPP at baseline. Surprisingly, neither IGF1 nor insulin levels were reversed to pretreatment levels during gonadal suppression. During gonadal suppression, an inverse relationship was found between changes in insulin and IGF1 levels. In addition, age- and puberty-adjusted IGF1 levels were moderately positively influenced by the GHRd3 allele in a copy numberresponse relationship in healthy girls. No influence of the GHRd3 allele was found on pubertal timing in neither normal nor early pubertal girls.

Increasing evidence support that IGF1 may be a positive modulator of pubertal timing in both rodents and humans $(4,7,8,9)$. In accordance with previous studies $(5,28)$, we found that girls with CPP had increased IGF1 levels compared with both age- and BA-matched healthy girls. In addition, girls with CPP had higher IGF1 levels than healthy girls even for
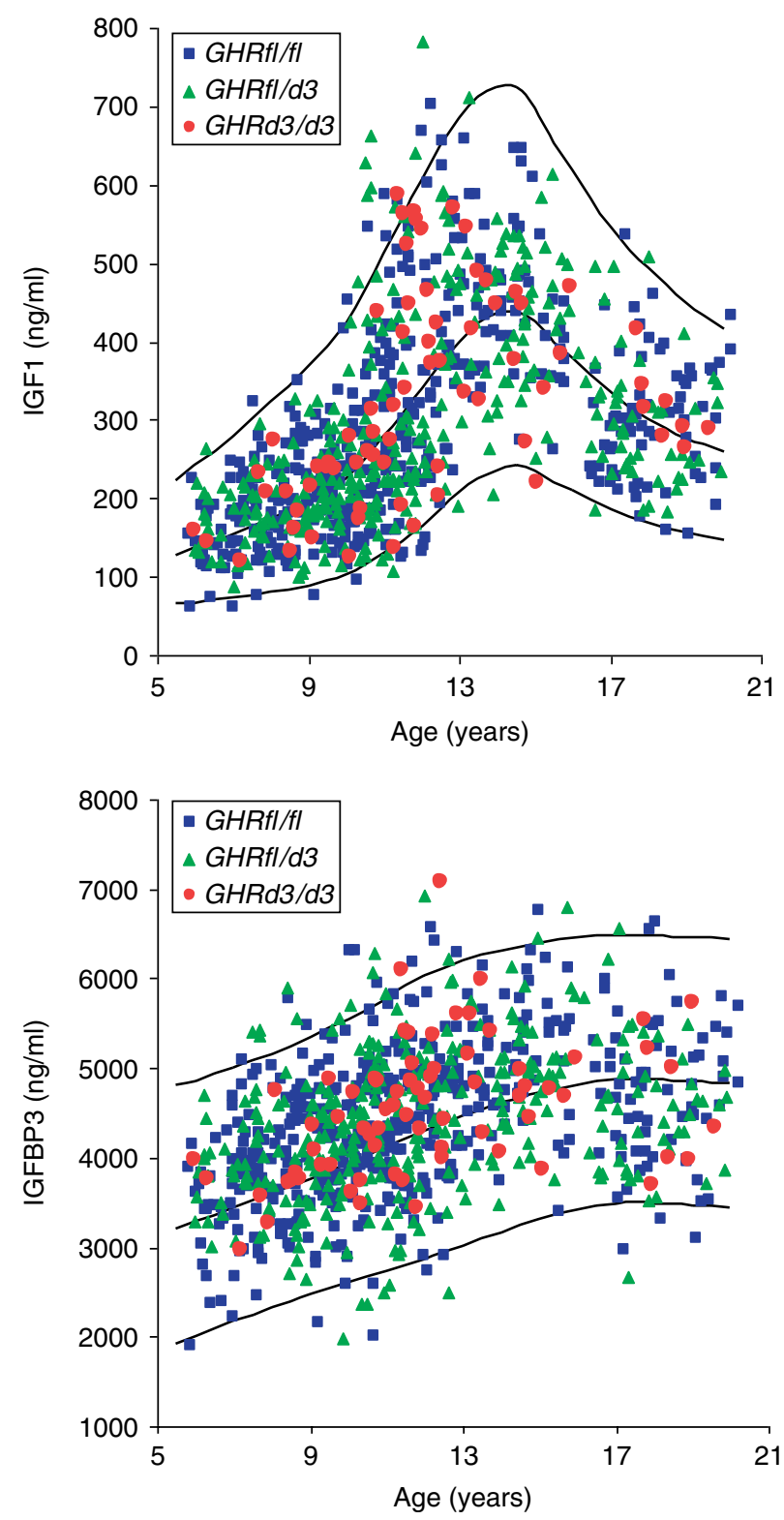

Figure 5 Influence of the GHR genotypes on IGF1 and IGFBP3 levels in relation to age in 911 healthy girls. Blue squares, green triangles, and red circles represent GHRfl/fI, GHRfl/d3, and $G H R d 3 / d 3$ genotypes respectively. Borderline significant higher age-adjusted IGF1 levels were found in GHRd3/d3 compared with $G H R f l / f I(8.4(-0.1-18.1) \%, P=0.06)$. No differences were found in IGFBP3 levels between genotypic groups. 
a given stage of breast development. In girls with onset of puberty between 8 and 9 years, no differences were found in IGF1 levels compared with puberty-matched controls, indicating that these girls may represent an early but normal pubertal variant with a lesser distinct phenotype than girls with overt CPP. Owing to the crosssectional design, the cause and effect relationship between pubertal timing and IGF1 levels could not be determined. Thus, the higher IGF1 levels in girls with CPP could be both causal as well as a consequence of early pubertal onset. In favor of a direct effect of IGF1 on pubertal timing, high prepubertal IGF1 predicts earlier age at menarche in healthy girls (4) and central and peripheral IGF1 infusion advances age at vaginal opening in female rodents $(8,9)$.

Similar to IGF1 levels, insulin levels were increased in girls with CPP at baseline compared with pubertymatched controls. In accordance with the previous studies on healthy children (14), IGF1 and insulin levels were strongly correlated in girls with $\mathrm{CPP}$ at the time of diagnosis. The major influence of GH on both IGF1 levels and glucose homeostasis is well documented (1). While GH antagonizes the insulin-mediated increase in peripheral glucose uptake by promoting lipolysis and free fatty acid oxidation (13), IGF1 may partly counteract these effects through negative feedback on GH secretion (29) as well as through direct insulin-like effects on glucose uptake (18). Although high GH secretion is most certainly involved in the increased IGF1 and insulin levels during normal puberty, previous studies have found normal to subnormal $\mathrm{GH}$ responses during $\mathrm{GH}$ stimulation tests in girls with $\mathrm{CPP}(5,30)$, indicating that increased GH secretion may not be the cause of the increased IGF1 and insulin levels found in the girls with CPP. Adiposity has a strong influence on glucose homeostasis. Accordingly, we found that higher adiposity was associated with higher insulin but not higher IGF1 levels after adjustment for breast stage in both healthy girls and girls with CPP. However, the higher adiposity found in girls with CPP did not solely explain the increased insulin levels in these girls.

In previous studies, IGF1 levels have shown diverging changes during GNRHa treatment $(5,28)$. In our CPP cohort, IGF1 levels were significantly reduced during the first 3 months of GNRHa treatment but tended to rebound toward pretreatment levels after 1 year of treatment. In contrast, insulin levels and adiposity increased significantly from the pretreatment visit to the 1-year evaluation without significant changes observed at the 3-month visit. Accordingly, short-term gonadal suppression in young adult women is not associated with changes in glucose homeostasis (31). Surprisingly, the persistent gonadal suppression and concomitant regression of sexual characteristics induced by the GNRHa treatment neither reversed IGF1 nor insulin to prepubertal levels. In addition, the individual pretreatment level of IGF1 and insulin persisted throughout the 1-year treatment period.
For insulin but not IGF1 levels this seems to be related to the degree of adiposity.

Pretreatment markers of advanced pubertal development such as advanced breast development and BA and higher baseline $\mathrm{E}_{2}$ levels predicted a greater decline in IGF1 levels and a greater increase in insulin levels during the first 3 months but not at later time points during treatment. Although this may indicate a direct effect of sex steroid withdrawal, GH secretion seems to be suppressed in parallel with the decrease in the activity of the hypothalamic-pituitary-gonadal (HPG) axis during GNRHa treatment (32). Accordingly, the positive influence of pubertal progression and $E_{2}$ priming on secretion of GH during stimulation testing is well documented (33). Thus, these changes may be secondary to a possible concomitant suppression of $\mathrm{GH}$ secretion rather than primarily related to $\mathrm{E}_{2}$ withdrawal.

The positive association between IGF1 and insulin levels at baseline was not present during GNRHa treatment. In fact, changes in IGF1 were inversely associated with changes in insulin levels during the 1-year follow-up period. Although this period represents both withdrawal of and continuous suppression of sex steroid levels, the inverse relationship, albeit insignificant, were found during all these distinct periods, which could indicate lack of statistical power rather than lack of true association. Thus, sex steroid withdrawal or the possible concomitant GH suppression induced by GNRHa treatment seems to change the relationship between these hormones. Accordingly, the positive association between IGF1 and insulin was strongest during mid-puberty in the healthy controls corresponding to the peak in GH secretion. Although a true causal relationship cannot be determined from these data, previous studies on adults with GH deficiency or GH insensitivity have shown decrease in insulin levels during IGF1 treatment (16), in accordance with direct insulin-like effects of IGF1. Thus, the relative hyperinsulinemia during GNRHa treatment seems to be associated with changes in IGF1. In addition, the relative insulin dominance over HPG and GH/IGF1 axis activation during GNRHa treatment may be implicated in the adverse changes in body composition previously reported in this and other cohorts of girls with CPP $(12,34,35)$. However, due to the small cohort size in our study, further studies are needed on the hormonal and body compositional changes induced by GNRHa treatment - as well as the reversibility upon discontinuation of treatment.

The unexplained findings of increased IGF1 levels in girls with CPP could be related to genetic effects. In the classical work by Dos Santos et al. (21), cells transfected with GHR dimers containing exon 3-deleted monomers had $\sim 30 \%$ augmented intracellular STAT activation after GH binding compared with full-length GHR dimers. The presence of the GHRd3 allele has previously been associated with higher insulin levels in normal children (15). In addition, homozygosity of the GHRd3 allele has been associated with higher childhood IGF1 levels and earlier pubertal onset evaluated by both clinical and 
biochemical markers in healthy boys (22). Accordingly, IGF1 levels in healthy girls were significantly higher in the GHRd3 homozygotes compared with both homo- and heterozygotes of the GHRfl allele in this study. However, no differences were found in age at onset of pubertal markers between the GHR genotypes in healthy girls. Although a previous genome-wide association study (GWAS) found that menarcheal age was associated with SNPs in the IGF1 locus (2), a recent GWAS meta-analysis did not support SNPs in genes related to the GH/IGF1 axis as significant contributors to the variation in timing of menarche (36). However, only very few case reports in girls with CPP have confirmed the same genetic variations in the genes associated with menarcheal timing in population-based studies (37), indicating that other genes may be involved in the development of CPP. However, the distribution of the GHRd3 genotypes was not significantly different between the healthy girls and the girls with CPP in this study, indicating that this genetic polymorphism was not involved in the pathogenesis of CPP nor the increased IGF1 levels seen in these girls. In fact, none of the 23 girls with early puberty was GHRd3 homozygous.

In summary, we present novel data on the interrelationship between IGF1 and insulin levels before and during gonadal suppression in girls with CPP. Girls with CPP had significantly higher IGF1 and insulin levels than age- and puberty-matched healthy girls. Surprisingly, these differences were neither reversed during gonadal suppression nor explained by the GHRd3 allele. Changes in IGF1 levels were inversely associated with changes in insulin levels during GNRHa treatment, which is in accordance with a positive effect of IGF1 on insulin sensitivity. Homozygosity of the GHRd3 allele was associated with significantly higher IGF1 levels during childhood and adolescence but not with earlier pubertal timing compared with GHRfl hetero- and homozygous healthy girls. Thus, the influence of IGF1 levels on pubertal timing still needs further elucidation.

\section{Declaration of interest}

The authors declare that there is no conflict of interest that could be perceived as prejudicing the impartiality of the research reported.

\section{Funding}

The Copenhagen Puberty Study received financial support by the Kirsten and Freddy Johansen Foundation and the Danish Medical Research Council (grant number 271-05-0337). Siemens Medical Solutions Diagnostics (Los Angeles, CA, USA) provided reagents for the IGF1 and IGFBP3 measurements.

\section{References}

1 Veldhuis JD, Roemmich JN, Richmond EJ \& Bowers CY. Somatotropic and gonadotropic axes linkages in infancy, childhood, and the puberty-adult transition. Endocrine Reviews 200627 101-140. (doi:10.1210/er.2005-0006)
2 Anderson CA, Zhu G, Falchi M, van den Berg SM, Treloar SA, Spector TD, Martin NG, Boomsma DI, Visscher PM \& Montgomery GW. A genome-wide linkage scan for age at menarche in three populations of European descent. Journal of Clinical Endocrinology and Metabolism 200893 3965-3970. (doi:10.1210/jc.2007-2568)

3 Veldhuis JD, Roemmich JN, Richmond EJ, Rogol AD, Lovejoy JC, Sheffield-Moore M, Mauras N \& Bowers CY. Endocrine control of body composition in infancy, childhood, and puberty. Endocrine Reviews 200526 114-146. (doi:10.1210/er.2003-0038)

4 Tam CS, de Zegher F, Garnett SP, Baur LA \& Cowell CT. Opposing influences of prenatal and postnatal growth on the timing of menarche. Journal of Clinical Endocrinology and Metabolism 2006 91 4369-4373. (doi:10.1210/jc.2006-0953)

5 Juul A, Scheike T, Nielsen CT, Krabbe S, Muller J \& Skakkebaek NE. Serum insulin-like growth factor I (IGF-I) and IGF-binding protein 3 levels are increased in central precocious puberty: effects of two different treatment regimens with gonadotropin-releasing hormone agonists, without or in combination with an antiandrogen (cyproterone acetate). Journal of Clinical Endocrinology and Metabolism 199580 3059-3067. (doi:10.1210/jc.80.10.3059)

6 Hiney JK, Ojeda SR \& Dees WL. Insulin-like growth factor I: a possible metabolic signal involved in the regulation of female puberty. Neuroendocrinology 199154 420-423. (doi:10.1159/ 000125924)

7 Divall SA, Williams TR, Carver SE, Koch L, Brüning JC, Kahn CR, Wondisford F, Radovick S \& Wolfe A. Divergent roles of growth factors in the GnRH regulation of puberty in mice. Journal of Clinical Investigation 2010120 2900-2909. (doi:10.1172/JCI41069)

8 Hiney JK, Srivastava V, Nyberg CL, Ojeda SR \& Dees WL. Insulinlike growth factor I of peripheral origin acts centrally to accelerate the initiation of female puberty. Endocrinology $19961373717-$ 3728. (doi:10.1210/en.137.9.3717)

9 Miller BH \& Gore AC. Alterations in hypothalamic insulin-like growth factor-I and its associations with gonadotropin releasing hormone neurones during reproductive development and ageing. Journal of Neuroendocrinology 200113 728-736. (doi:10.1046/j. 1365-2826.2001.00686.x)

10 Hiney JK, Srivastava VK, Pine MD \& Les DW. Insulin-like growth factor-I activates KiSS-1 gene expression in the brain of the prepubertal female rat. Endocrinology 2009150 376-384. (doi:10.1210/en.2008-0954)

11 Frontini MG, Srinivasan SR \& Berenson GS. Longitudinal changes in risk variables underlying metabolic Syndrome X from childhood to young adulthood in female subjects with a history of early menarche: the Bogalusa Heart Study. International Journal of Obesity and Related Metabolic Disorders 200327 1398-1404. (doi:10.1038/sj.ijo.0802422)

12 Sorensen K, Mouritsen A, Mogensen SS, Aksglaede L \& Juul A. Insulin sensitivity and lipid profiles in girls with central precocious puberty before and during gonadal suppression. Journal of Clinical Endocrinology and Metabolism 201095 3736-3744. (doi:10. 1210/jc.2010-0731)

13 Moller N \& Jorgensen JO. Effects of growth hormone on glucose, lipid, and protein metabolism in human subjects. Endocrine Reviews 200930 152-177. (doi:10.1210/er.2008-0027)

14 Moran A, Jacobs DR Jr, Steinberger J, Cohen P, Hong C-P, Prineas R \& Sinaiko AR. Association between the insulin resistance of puberty and the insulin-like growth factor-I/growth hormone axis. Journal of Clinical Endocrinology and Metabolism 200287 4817-4820. (doi:10.1210/jc.2002-020517)

15 Sorensen K, Aksglaede L, Munch-Andersen T, AachmannAndersen NJ, Leffers H, Helge JW, Hilsted L \& Juul A. Impact of the growth hormone receptor exon 3 deletion gene polymorphism on glucose metabolism, lipids, and insulin-like growth factor-I levels during puberty. Journal of Clinical Endocrinology and Metabolism 200994 2966-2969. (doi:10.1210/jc.2009-0313)

16 Hussain MA, Schmitz O, Mengel A, Glatz Y, Christiansen JS, Zapf J \& Froesch ER. Comparison of the effects of growth hormone and 
insulin-like growth factor I on substrate oxidation and on insulin sensitivity in growth hormone-deficient humans. Journal of Clinical Investigation 199494 1126-1133. (doi:10.1172/JCI117427)

17 Mauras N \& Haymond MW. Are the metabolic effects of GH and IGF-I separable? Growth Hormone \& IGF Research 200515 19-27. (doi:10.1016/j.ghir.2004.12.003)

18 Mauras N, Martinez V, Rini A \& Guevara-Aguirre J. Recombinant human insulin-like growth factor I has significant anabolic effects in adults with growth hormone receptor deficiency: studies on protein, glucose, and lipid metabolism. Journal of Clinical Endocrinology and Metabolism 200085 3036-3042. (doi:10.1210/jc.85.9.3036)

19 Savage MO, Blum WF, Ranke MB, Postel-Vinay MC, Cotterill AM, Hall K, Chatelain PG, Preece MA \& Rosenfeld RG. Clinical features and endocrine status in patients with growth hormone insensitivity (Laron syndrome). Journal of Clinical Endocrinology and Metabolism 199377 1465-1471. (doi:10.1210/jc.77.6.1465)

20 Zhou Y, Xu BC, Maheshwari HG, He L, Reed M, Lozykowski M, Okada S, Cataldo L, Coschigamo K. Wagner TE, Baumann G \& Kopchick JJ. A mammalian model for Laron syndrome produced by targeted disruption of the mouse growth hormone receptor/ binding protein gene (the Laron mouse). PNAS $1997 \mathbf{9 4}$ 13215-13220. (doi:10.1073/pnas.94.24.13215)

21 Dos SC, Essioux L, Teinturier C, Tauber M, Goffin V \& Bougneres P. A common polymorphism of the growth hormone receptor is associated with increased responsiveness to growth hormone. Nature Genetics 200436 720-724. (doi:10.1038/ng1379)

22 Sorensen K, Aksglaede L, Petersen JH, Leffers H \& Juul A. The exon 3 deleted growth hormone receptor gene is associated with small birth size and early pubertal onset in healthy boys. Journal of Clinical Endocrinology and Metabolism $2010952819-2826$. (doi:10.1210/jc.2009-2484)

23 Jensen RB, Vielwerth S, Larsen T, Greisen G, Leffers H \& Juul A. The presence of the $\mathrm{d} 3$-growth hormone receptor polymorphism is negatively associated with fetal growth but positively associated with postnatal growth in healthy subjects. Journal of Clinical Endocrinology and Metabolism 200792 2758-2763. (doi:10. 1210/jc.2007-0176)

24 Toyoshima MT, Castroneves LA, Costalonga EF, Mendonca BB, Arnhold IJ \& Jorge AA. Exon 3-deleted genotype of growth hormone receptor (GHRd3) positively influences IGF-1 increase at generation test in children with idiopathic short stature. Clinical Endocrinology 200767 500-504. (doi:10.1111/j.1365-2265. 2007.02915.x)

25 Aksglaede L, Sorensen K, Petersen JH, Skakkebaek NE \& Juul A. Recent decline in age at breast development: the Copenhagen Puberty Study. Pediatrics 2009123 e932-e939. (doi:10.1542/ peds.2008-2491)

26 Marshall WA \& Tanner JM. Variations in pattern of pubertal changes in girls. Archives of Disease in Childhood 196944 291-303. (doi:10.1136/adc.44.235.291)

27 Pantel J, Machinis K, Sobrier ML, Duquesnoy P, Goossens M \& Amselem S. Species-specific alternative splice mimicry at the growth hormone receptor locus revealed by the lineage of retroelements during primate evolution. Journal of Biological Chemistry 2000275 18664-18669. (doi:10.1074/jbc.M001615200)

28 Kanety H, Karasik A, Pariente C \& Kauschansky A. Insulin-like growth factor-I and IGF binding protein-3 remain high after $\mathrm{GnRH}$ analogue therapy in girls with central precocious puberty. Clinical Endocrinology 199645 7-12. (doi:10.1111/j.1365-2265.1996. tb02053.x)

29 Yakar S, Liu JL, Fernandez AM, Wu Y, Schally AV, Frystyk J, Chernausek SD, Mejia W \& Le Roith D. Liver-specific igf-1 gene deletion leads to muscle insulin insensitivity. Diabetes 200150 1110-1118. (doi:10.2337/diabetes.50.5.1110)

30 Kamp GA, Manasco PK, Barnes KM, Jones J, Rose SR, Hill SC \& Cutler GB Jr. Low growth hormone levels are related to increased body mass index and do not reflect impaired growth in luteinizing hormone-releasing hormone agonist-treated children with precocious puberty. Journal of Clinical Endocrinology and Metabolism 199172 301-307. (doi:10.1210/jcem-72-2-301)
31 Toth MJ, Cooper BC, Pratley RE, Mari A, Matthews DE \& Casson PR. Effect of ovarian suppression with gonadotropin-releasing hormone agonist on glucose disposal and insulin secretion. American Journal of Physiology. Endocrinology and Metabolism 2008294 E1035-E1045. (doi:10.1152/ajpendo.00789.2007)

32 Mansfield MJ, Rudlin CR, Crigler JF Jr, Karol KA, Crawford JD, Boepple PA \& Crowley WF Jr. Changes in growth and serum growth hormone and plasma somatomedin-C levels during suppression of gonadal sex steroid secretion in girls with central precocious puberty. Journal of Clinical Endocrinology and Metabolism 198866 3-9. (doi:10.1210/jcem-66-1-3)

33 Coutant R, de Casson FB, Rouleau S, Douay O, Mathieu E, Gatelais F, Bouhours-Nouet N, Voinot C, Audran M \& Limal JM. Divergent effect of endogenous and exogenous sex steroids on the insulin-like growth factor I response to growth hormone in short normal adolescents. Journal of Clinical Endocrinology and Metabolism 200489 6185-6192. (doi:10.1210/jc.2004-0814)

34 van der Sluis IM, Boot AM, Krenning EP. Drop SL \& de Muinck KeizerSchrama SM. Longitudinal follow-up of bone density and body composition in children with precocious or early puberty before, during and after cessation of GnRH agonist therapy. Journal of Clinical Endocrinology and Metabolism 200287 506-512. (doi:10.1210/ jc.87.2.506)

35 Sorensen K, Andersson AM, Skakkebaek NE \& Juul A. Serum sex hormone-binding globulin levels in healthy children and girls with precocious puberty before and during gonadotropin-releasing hormone agonist treatment. Journal of Clinical Endocrinology and Metabolism 200792 3189-3196. (doi:10.1210/jc.2007-0231)

36 Elks CE, Perry JR, Sulem P, Chasman DI, Franceschini N, He C, Lunetta KL, Visser JA, Byrne EM, Cousminer DL, Gudbjartsson DF, Esko T, Feenstra B, Hottenga JJ, Koller DL, Kutalik Z, Lin P, Mangino M, Marongiu M, McArdle PF, Smith AV, Stolk L, van Wingerden SH, Zhao JH, Albrecht E, Corre T, Ingelsson E, Hayward C, Magnusson PK, Smith EN, Ulivi S, Warrington NM, Zgaga L, Alavere H, Amin N, Aspelund T, Bandinelli S, Barroso I, Berenson GS, Bergmann S, Blackburn H, Boerwinkle E, Buring JE, Busonero F, Campbell H, Chanock SJ, Chen W, Cornelis MC, Couper D, Coviello AD, d'Adamo P, de Faire U, de Geus EJ, Deloukas P, Döring A, Smith GD, Easton DF, Eiriksdottir G, Emilsson V, Eriksson J, Ferrucci L, Folsom AR, Foroud T, Garcia M, Gasparini P, Geller F, Gieger C, GIANT Consortium, Gudnason V, Hall P, Hankinson SE, Ferreli L, Heath AC, Hernandez DG, Hofman A, Hu FB, Illig T, Järvelin MR, Johnson AD, Karasik D, Khaw KT, Kiel DP, Kilpeläinen TO, Kolcic I, Kraft P, Launer LJ, Laven JS, Li S, Liu J, Levy D, Martin NG, McArdle WL, Melbye M, Mooser V, Murray JC, Murray SS, Nalls MA, Navarro P, Nelis M, Ness AR, Northstone K, Oostra BA, Peacock M, Palmer LJ, Palotie A, Paré G, Parker AN, Pedersen NL, Peltonen L, Pennell CE, Pharoah P, Polasek O, Plump AS, Pouta A, Porcu E, Rafnar T, Rice JP, Ring SM, Rivadeneira F, Rudan I, Sala C, Salomaa V, Sanna S, Schlessinger D, Schork NJ, Schork NJ, Scuteri A, Segrè AV, Shuldiner AR, Soranzo N, Sovio U, Srinivasan SR, Strachan DP, Tammesoo ML, Tikkanen E, Toniolo D, Tsui K, Tryggvadottir L, Tyrer J, Uda M, van Dam RM, van Meurs JB, Vollenweider P, Waeber G, Wareham NJ, Waterworth DM, Weedon MN, Wichmann HE, Willemsen G, Wilson JF, Wright AF, Young L, Zhai G, Zhuang WV, Bierut LJ, Boomsma DI, Boyd HA, Crisponi L, Demerath EW, van Duijn CM, Econs MJ, Harris TB, Hunter DJ, Loos RJ, Metspalu A, Montgomery GW, Ridker PM, Spector TD, Streeten EA, Stefansson K, Thorsteinsdottir U, Uitterlinden AG, Widen E, Murabito JM, Ong KK \& Murray A. Thirty new loci for age at menarche identified by a metaanalysis of genome-wide association studies. Nature Genetics 201042 1077-1085. (doi:10.1038/ng.714)

37 Silveira LF, Trarbach EB \& Latronico AC. Genetics basis for GnRHdependent pubertal disorders in humans. Molecular and Cellular Endocrinology 2010324 30-38. (doi:10.1016/j.mce.2010.02.023)

Received 21 December 2011

Accepted 29 February 2012 